\title{
Manta dos afetos: uma abordagem dos afetos e sexualidade na primeira infância
}

\section{Affections blanket project: an approach of affections and sexuality in early childhood}

\author{
Carmo Cunha*, Carina Parente**, Luísa Santos *** \\ *Agrupamento Escolas Monte da Ola, ${ }^{* *}$ Gabinete de Atendimento à Família, *** Escola Superior de Saúde - Instituto Politécnico \\ Viana do Castelo - Portugal
}

\begin{abstract}
Resumo
O presente artigo propõe-se apresentar o Projeto "Manta dos afetos”, no âmbito da Educação Sexual com crianças de 4/5 anos num jardim de infância, tendo contado com a participação das famílias. Foi operacionalizado no ano letivo 2013-2014 numa turma de 18 crianças e visa determinar áreas a valorizar num programa de educação sexual para pré-escolares, verificar a adequação dos materiais pedagógicos e a sua utilidade para uma abordagem em casa. Recorreu-se à metodologia de aprendizagem pela ação, privilegiando-se as atividades lúdicas e participativas. Os resultados revelaram vantagens significativas para as crianças, ao nível do autoconhecimento e fortalecimento das relações interpessoais.
\end{abstract}

Palavras chave: afetos, sexualidade, parentalidade positiva, pré-escolar

\begin{abstract}
This article presents the "Affections Blanket" Project about Sexual Education developed in the 2013-2014 school year with a class of 18 children aged four and five years old, on a kindergarten. Its goals were to determine the priority areas for action in a sexual education program with pre-school children, verify the adequacy of the newly created teaching materials and their usefulness to an approach at home. This project involved the children's families and applied the "action-learning" methodology with participatory and recreational practices. The results have shown clear benefits regarding children's self-consciousness and allowed the strengthening of interpersonal relationships.
\end{abstract}

Keywords: affections, sexuality, positive parenting, preschool

A vivência da sexualidade é inerente ao indivíduo e tem início bem antes do seu nascimento, ainda na vida intra-uterina (ME-GTES, 2007), acompanhando o Ser Humano durante toda a sua vida. Partindo desse pressuposto, a educação sexual (ES), sendo um processo contínuo e inconcluso, requer a ação e o contributo de todos os parceiros, numa perspetiva participativa e articulada.

Em Portugal, as diretrizes emanadas pela tutela consideram a escola como espaço privilegiado para uma "abordagem formal, estruturada, intencional e adequada, de um conjunto de questões relacionadas com a sexualidade humana” (Ministério da Educação, Ministério da Saúde, APF, \& CAN, 2000, p. 26), sendo de realçar um maior envolvimento das escolas e o esforço dos professores para a promoção de atividades neste âmbito nos últimos anos (Vilar \& Ferreira, 2009). Todavia importa sublinhar que o enquadramento legal vigente, que preconiza e regulamenta a Educação Sexual em meio escolar, contempla apenas a sua implementação desde o ensino básico e nos níveis subsequentes, sendo gritante a lacuna legal que exclui a educação pré-escolar deste processo, negligenciando um nível de educação que é tomado como "primeira etapa da educação básica” como sublinha a Lei Quadro da Educação Pré-escolar (Lei $n^{\circ}$ 5/97 de 10 de fevereiro). Este hiato não deve obstar à abordagem de uma educação para os afetos e para a sexualidade, mas antes constituir um aliciante desafio, ao ser encarada como uma janela de oportunidades para a promoção de uma vivência com significado positivo.

O documento Health for all in the 21st century, publicado pela Organização Mundial de Saúde (OMS) destaca o papel relevante dos educadores - desde o pré-escolar até ao ensino superior - e o seu "contributo para o desenvolvimento dos indivíduos e no incremento de valores, conhecimentos e competências em matéria de promoção da Saúde” (WHO, 1999, p. 155). São apontadas metas muito claras no que toca aos vários níveis de educação, concretamente na educação pré-escolar, que em 2015, pelo menos 50\% das crianças dessa faixa etária tenham a oportunidade de frequentar estabelecimentos de ensino Promotores de Saúde. As Orientações Curriculares para a Educação Pré-escolar propõem a Área de Formação Pessoal e Social como área integradora e transversal do processo educativo. Esta sublinha algumas vertentes, entre as quais há a destacar a educação para os valores (procura do bem próprio e bem coletivo), a educação multicultural e para a cidadania, onde se inscreve a abordagem da educação sexual e para a saúde. Neste domínio pretende-se contribuir para a formação consciente e responsável da criança com vista à adoção de comportamentos e escolhas de vida saudáveis. É neste entendimento que é preconizada a educação sexual e para os afetos desde a idade pré-escolar, tirando partido da proximidade relacional e de um clima aberto ao diálogo que é manifesto entre escola e família neste nível etário (R. Marques, 2001). Na Europa, os programas de educação sexual mais abrangentes que demonstram maior eficácia são desenvolvidos nos países nórdicos e do Benelux (Bélgica, Holanda, Luxemburgo), destacando a Holanda onde a implementação se inicia aos quatro anos de idade, com enfoque nos aspetos do conhecimento do corpo, autoimagem e relações 
interpessoais - programa Relationships \& Sexuality (Beaumont \& Maguire, 2013) e sendo de caráter obrigatório a partir dos cinco/seis anos na Bélgica Luxemburgo, Suécia, França e Irlanda (IPPF, 2006).

\section{Método}

\section{Apresentação do projeto: objetivos; estrutura e aspetos metodológicos}

O Projeto Manta dos Afetos, integrado num grande projeto intitulado Algodão Doce, nasceu como fruto de uma reflexão acerca da situação epidemiológica por altura dos 30 anos do VIH/SIDA em Portugal, por uma equipa multidisciplinar, em Viana do Castelo. Constatando-se que o diagnóstico tardio da infeção é uma realidade ainda por ultrapassar no nosso país, é essencial apostar na sensibilização, o mais precocemente possível, junto dos que têm responsabilidade na educação - educadores de infância e pais.

O referido projeto teve como populações alvo os educadores de infância, os pais e as crianças com aproximadamente cinco anos de idade que frequentam o pré-escolar. Relativamente à intervenção com as crianças, implementou-se a Manta dos Afetos, que espelhava a vontade e o esforço para abordar a educação para a sexualidade e os afetos com crianças da primeira infância, com a colaboração direta das famílias, como parceiros privilegiados neste projeto.

Este foi desenvolvido no espaço educativo do pré-escolar, com uma amostra de dezoito crianças integrantes de um grupo-turma (onze raparigas e sete rapazes), sendo que treze tinham cinco anos de idade e os restantes elementos apenas quatro. De ressaltar que a participação das crianças no presente estudo foi autorizada pelos pais através de consentimento informado, por escrito, garantindo a confidencialidade e uso exclusivo dos dados para a investigação. A equipa educativa era constituída pela educadora responsável pela turma, por uma assistente operacional e duas estagiárias de educação pré-escolar. Esta ação contou também com a estreita colaboração das dezoito famílias, das quais dez eram famílias nucleares, cinco com a responsabilidade parental exercida apenas pela progenitora e três eram monoparentais femininas. A Manta dos Afetos tinha como objetivos gerais proporcionar às crianças uma descoberta informada e responsável da sexualidade e dos afetos, quer individualmente, quer no grupo turma, e ainda contribuir para o desenvolvimento de competências pessoais e sociais nas crianças e na familia.

Os objetivos específicos eram aprofundar conhecimentos sobre o seu corpo, a sua identidade sexual, o significado afetivo da família e tipologias familiares, os fenómenos básicos da reprodução humana; promover atitudes de respeito e de aceitação de Si e do Outro; fomentar atitudes de tolerância e de valorização das expressões de afeto na família e no grupo de amigos; estimular a reflexão sobre os papéis de género; incrementar competências para expressar e partilhar ideias, emoções e sentimentos; desenvolver competências comunicativas e potenciar competências para agir com autonomia e assertividade em diversos contextos de sociabilidade.

Tendo como premissa base que as crianças desta idade constroem relações interpessoais de grande intensidade, a proliferação destas relações é responsável por certas conquistas, designadamente a compreensão do sentido de grupo, um maior controlo emocional, a manifestação de maior autonomia, capacidade de iniciativa e emergência de lideranças (Hohmann \& Weikart, 1997). Paralelamente, surge a interação lúdica como um caminho facilitador da tomada de consciência de si próprio na relação com o outro, incluindo a descoberta do corpo. A construção do conhecimento decorre de uma forte curiosidade e desejo de saber, que se corporiza na imensidão de questões que levantam, na busca de soluções para as suas inquietações, na compreensão de fenómenos do quotidiano, na formulação de hipóteses. É um período de forte apetência para as competências comunicativas, pois a criança gosta de utilizar a linguagem para expressar e comunicar ideias, vivências, sentimentos, emoções, receios, desejos (A. M. Marques, Vilar, \& Forreta, 2002). Neste sentido, importa sublinhar que foram tidos em atenção os interesses e as necessidades intrínsecas das crianças desta idade, numa perspetiva de currículo em espiral, ou seja, qualquer tópico ou conteúdo pode ser abordado em qualquer idade e retomado ao longo do percurso de aprendizagem com outro nível de profundidade e grau de complexidade (Ostermann \& Cavalcanti, 2010). As diferentes abordagens realizadas incidiram sobre temáticas como a descoberta do corpo e aspetos alusivos à anatomia humana, a identidade sexual, perceção de semelhanças e diferenças e as representações associadas ao género; conceito de família e tipologias; os fenómenos da conceção, gestação e parto. Estes conteúdos foram trabalhados durante dez encontros, entre março e junho de 2014, cada um com a duração de um dia letivo (período entre as 9 horas e as $15 \mathrm{~h} 30 \mathrm{~m}$ ). Todavia, salienta-se o facto do desenvolvimento e consolidação de algumas atividades práticas com as crianças se terem estendido por um período mais lato de tempo.

O modelo de intervenção educativa, configurado na pedagogia em participação, privilegiou a aprendizagem pela ação, tomando a criança como "autora e coconstrutora do seu conhecimento" e adotando "práticas de aprendizagem cooperada" (Figueiredo, Morais, \& Garcia, 2005, p. 3019). Relativamente à metodologia de intervenção adotaram-se processos de aprendizagem assentes em estratégias dinâmicas, com recurso a propostas ativas e participativas. Foi enfatizada a vertente lúdica, tirando partido da atividade do brincar, a fim de proporcionar momentos de intencionalidade educativa cheios de significado para a criança (Brito \& Santos, 2012). Foram construídos materiais exploratórios para o projeto (dois bonecos silhueta: o menino Yuri e a menina Kali) e criados alguns recursos específicos para cada uma das abordagens (jogos, histórias, ilustrações), que potenciassem a concretização das tarefas e suscitassem o envolvimento das crianças, de maneira que estas tivessem uma "experiência de aprendizagem profunda, motivada, intensa e duradora” (Laevers, 1994, citado por Oliveira-Formosinho, 2004, p. 86). Os 
conhecimentos prévios que as crianças utilizam para interpretar a realidade foram o ponto de partida para a aprendizagem. Ao longo do processo, os saberes de partida ("o que nós já sabemos”) ganharam nova forma, aproximando-se cada vez mais do conhecimento científico. Neste sentido, no início de cada momento de intervenção promovia-se a motivação das crianças com a narração de uma história, em que os protagonistas (Yuri e Kali) traziam alguma vivência, episódio do quotidiano ou situação de conflito. Os personagens apelavam à participação das crianças, envolviam-nas na trama e propunham a construção de um desenlace para a história.

No primeiro momento, os "anfitriões - Yuri e Kali" desafiaram as crianças a descobrirem o seu corpo e, através da experimentação, os bonecos foram despidos e vestidos. O grupo nomeou as diferentes partes do corpo, descobrindo a terminologia correta, inclusivamente os genitais. As crianças fizeram descobertas entre si, com recurso ao espelho vertical da sala, observando-se, tocando-se e registando caraterísticas físicas de cada um (exemplo, cor dos olhos, tipo de cabelo, estatura, formato do corpo). Abordou-se a importância dos cuidados pessoais com o nosso corpo e discutiram-se alguns fatores de proteção e de risco (Frade, Marques, Alverca, \& Vilar, 2009) (Morales \& Guijarro, 2003).

A identidade sexual "Ser menino ou menina" e as representações sociais de género foram os conteúdos trabalhados no segundo momento de intervenção. Numa perspetiva comparativa relativamente ao género foram abordados os seguintes aspetos: as cores, os brinquedos, o vestuário, calçado e acessórios, as profissões. No seguimento e tendo em atenção a sua função pedagógica, as crianças construíram uma Loja de Brinquedos não sexista com uma nova organização e disposição (Rights, 2004) (Fernández \& Sanchez, 2009).

A abordagem da família, conceito e tipologias, foram o enfoque da terceira sessão, procurando-se conhecer os vários tipos de situação familiar, identificando a própria. Além disso, foi construída uma rede de significados imbricados ao conceito chave e partilharam-se ideias sobre sentimentos como a amizade e o amor. Refletiu-se ainda sobre o significado de "amar..." e "ser amado por...”, permitindo que cada criança expressasse os seus sentimentos (Louro, 2012) (Ferreira \& Salvaterra, 2004).

O momento quatro centrou-se nos fenómenos do começo da vida, explorando-se a conceção, a gestação e o parto. Assim, realizaram-se pesquisas bibliográficas na biblioteca da escola. De realçar que em especial nesta sessão colaboraram alguns pais: uma mãe grávida e um casal que partilharam com as crianças a sua experiência relacionada com o momento da gravidez e do parto (Winston, 2004) (Matos, 2006).

Todas as atividades tiveram em conta contextos e recursos significativos, com propostas que fizessem sentido para a criança, constituindo experiências de fruição pela aprendizagem. Revestiram-se ainda de um caráter integrador, isto é, potenciaram o desenvolvimento de competências de outras áreas e domínios (expressão plástica, comunicação verbal, abordagem à escrita, matemática, conhecimento do mundo), com maior incidência nas competências da formação pessoal e social. No decurso da implementação com as crianças foram apresentadas tarefas para pais e filhos, para serem concretizadas em contexto familiar. Com estas pretendia-se reforçar e consolidar as vivências e aprendizagens feitas no jardim-de-infância, para além de dar conta aos pais dos conteúdos que iam sendo tratados no espaço escolar e a forma como eram abordados. A par destas propostas, as crianças, uma vez por semana, escolhiam um objeto pertencente ao Yuri e à Kali que levavam para casa como recurso para motivar e intensificar o diálogo entre a criança e os pais sobre assuntos ligados à sexualidade e aos afetos. Estas propostas de trabalho consistiram na realização de uma simples ficha de identificação da criança “Quem sou eu”, na experimentação de um jogo digital (jogo das diferenças de género), na medição dos elementos da nossa família (Palmo a palmo... conheço a minha família), na partilha de um registo fotográfico documentando um momento familiar marcante e na criação de uma poesia dedicada à criança.

Este trabalho circunscreve-se numa perspetiva de investigação qualitativa-interpretativa, reconhecendo três caraterísticas fundamentais neste estudo apontadas por Jacob: a investigação ocorre num cenário natural, as perspetivas dos participantes são tidas em linha de conta e as questões do estudo emergem no desenvolvimento da própria investigação (Jacob, 1998). Por outro lado, este tipo de investigação torna-se "acessível, não simplesmente porque está escrito numa linguagem dirigida não apenas a especialistas, mas também porque, em vez de encarar os educadores de infância como sujeitos da investigação, privilegia as interpretações dos mesmos" (Spodek, 2002, p. 1040). As técnicas de recolha de dados utilizadas foram essencialmente a análise documental e observação participante. Os dados coligidos basearam-se nos registos gráficos e produções das crianças que compõem o seu portefólio de avaliação (Hohmann \& Weikart, 1997), tendo sido dada prioridade a estas fontes de informação, subsidiadas pelos registos áudio, vídeo e fotográficos e algumas notas de campo. Relativamente aos pais, optou-se pelo recurso à entrevista semiestruturada para obter as suas narrativas acerca da pertinência do trabalho desenvolvido com os seus filhos.

\section{Resultados}

A análise documental permitiu verificar que as crianças adquiriram novas aprendizagens, designadamente sobre o conhecimento do corpo e da sua anatomia, conceito e tipologias de famílias, fenómenos da reprodução, gestação e nascimento. Existiu ainda um alargamento do léxico ativo (terminologia nova adquirida ao longo do projeto, a exemplo: pénis e vagina, família de acolhimento, instituições, adoção, cordão umbilical, parto, mamífero) e ampliação de saberes ao nível do Conhecimento do Mundo (área relacionada com a curiosidade natural da criança e o seu desejo de saber Orientações Curriculares para a Educação Pré-escolar, Ministério da Educação, 1997): estilos e costumes da vida familiar; fenómenos da vida social como as atividades profissionais, o lazer, a moda; reconhecimento dos fatores de proteção e cuidados pessoais com o corpo; 
começo da vida. Também se produziu uma mudança conceptual significativa e com maior rigor científico, pois na avaliação geral do projeto as crianças corroboram a ideia de que aprenderam muitas coisas: "que as famílias são todas diferentes, que há famílias que vão a instituições buscar filhos, como crescem e nascem os bebés, alguns nomes verdadeiros para partes do corpo, descobrimos o nosso corpo, que há profissões que podem ser "nossas" (homens) e de mulheres...". Todavia a maioria das crianças referiram como descobertas mais marcantes a designação dos genitais (seis crianças do grupo) e a gestação e nascimento dos bebés (doze crianças). A clarificação de conceitos foi outra das conquistas do projeto, uma vez que as crianças primeiramente refletiram, partilharam ideias e analisaram em grupo noções como Família, Igualdade, Amor, que posteriormente plasmaram nos trabalhos plásticos que produziram. Este despontar de novas ideias foi reforçado com o contributo dos pais e através das atividades propostas para realização no contexto familiar. A par da análise dos documentos produzidos pelas crianças, a observação participante e os registos audiovisuais foram recursos de suma importância, que possibilitaram obter conhecimento decorrente da interação entre o investigador e o grupo alvo de investigação. Tais técnicas de recolha de dados têm o privilégio de colocar o investigador no seio da ação e tirar vantagem da proximidade que estabelece com o grupo de estudo, conhecendo a sua contextualização, conforme corroboram Souza, Kantorski e Villar (Souza, Kantorski, \& Villar Luis, 2011). Verificamos, portanto, que as crianças evidenciavam no término do projeto melhores competências sociais, traduzidas em atitudes de maior participação e envolvimento nas atividades e na vida do grupo. Conquistaram uma consciência mais forte de si, do seu corpo e da sua identidade e consequentemente a sua autoestima ficou mais reforçada. As relações interpessoais entre pares ficaram mais vincadas e partilhavam com maior espontaneidade as suas ideias e emoções. A coesão no grupo cresceu, esbatendo-se um pouco a existência dos pequenos grupos por influência de género. As suas brincadeiras tornaram-se mais partilhadas, existindo uma maior cumplicidade. A proximidade relacional com os adultos da sala também se intensificou, retratando-se no espírito de abertura e diálogo que se estabeleceu e no clima de confiança que se vivenciou. A educação para a cidadania esteve implícita ao longo de todo o projeto, enfatizando os valores da tolerância, igualdade e paridade entre sexos e promovendo a abolição de preconceitos e o combate a atitudes de discriminação. Houve um grande enfoque na partilha e questionamento de ideias, que muitas vezes não foram consensuais, designadamente no que se refere à abordagem das representações sociais de género, pois grande parte dos rapazes não aceitava que meninos "usassem sapatinhos cor de rosa, com lacinhos". Debates semelhantes existiram, ricos e sem constrangimentos, donde sobressaiu sempre o princípio da valorização de todas as posições, do respeito pelo Outro e do direito à diferença. Os resultados evidenciados permitiram também concluir que os materiais pedagógicos criados para o projeto (os personagens Yuri e Kali e objetos pessoais) foram adjuvantes de toda a ação desenvolvida, contribuindo para a construção de conhecimento, além do caráter lúdico e afetivo de que se revestiram. As crianças entusiasmavam-se sempre que o Yuri e a Kali chegavam à sala e ansiavam pelo dia negociado para levar os seus pertences para casa (sextas feiras), gerando-se uma relação de familiaridade entre os bonecos-mediadores e as crianças. Quanto ao envolvimento dos pais, não foi possível inferir a qualidade da sua participação no projeto, no entanto os pais aderentes manifestaram através de entrevista o seu total agrado em colaborar no mesmo, apesar dos seus receios iniciais. Sublinharam os ganhos alcançados no que toca à abertura de diálogo e proximidade com os seus filhos e uma maior capacitação para tratar as questões da sexualidade e dos afetos.

\section{Conclusão}

A educação sexual, no que se refere à sua promoção e desenvolvimento em meio escolar, encontra sustentação legal, num quadro jurídico nacional e internacional, sendo condição indispensável para se alcançar o bem-estar e a saúde. O seu desenvolvimento em contexto formal assume contornos de caráter intencional e estruturado, cuja trama educativa se desenrola a partir do primeiro ciclo. A evidência empírica enfatiza as vantagens da intervenção em idades mais precoces, pelo que se procurou explorar a pertinência da sua implementação desde o pré-escolar, tirando partido das oportunidades e desafios em contexto pedagógico e aceitando este repto como um investimento educativo positivo e exequível. O desenvolvimento do projeto representou uma novidade para as crianças, que se sentiram verdadeiras protagonistas na ação, tendo estas vivido com grande satisfação e prazer todas as conquistas realizadas, desejando aprender mais, para ser e fazer melhor. Simultaneamente, este projeto constituiu uma experiência gratificante para os pais, que revelaram surpresa com os resultados alcançados e admitiram que a mesma superou as suas expectativas e preocupações iniciais. Além disso, sublinharam como vantagem a destacar a oportunidade de estreitar relações quer com a equipa educativa, quer com outros pais, dado a abordagem de educação sexual ter acontecido numa ação conjunta com a escola. Ao nível dos educadores de infância, o projeto contribuiu para a revalidação da importância do papel desempenhado, alargando perspetivas e melhorando a sua prática autorreflexiva.

Importa ainda apresentar as limitações do presente estudo. A primeira prende-se com o fator tempo, pois tendo em consideração a diversidade e a complexidade das temáticas a abordar se considera que os quatro meses de implementação foram insuficientes. Por outro lado, a participação dos pais não foi muito consistente no que toca às atividades de consolidação em casa, principalmente quando as tarefas envolveram questões associadas às representações socias de género. Também se pode considerar como limitação o facto de o estudo ter sido desenvolvido no contexto de trabalho da investigadora, dada a proximidade afetiva e envolvimento emocional com os participantes do estudo, 
apesar do esforço realizado no sentido de atuar com neutralidade e cuidado e isenção na análise dos dados e sua interpretação. Para terminar apresenta-se como proposta a disseminação do projeto "Manta dos Afetos" junto de outros estabelecimentos de educação pré-escolar, dando a oportunidade aos docentes de obterem orientação na prática nesta área de intervenção.

\section{Referências bibliográficas}

Beaumont, K., \& Maguire, M. (2013). Policies for Sexuality Education in the European Union. Brussels: European Parliament Retrieved from http://www.europarl.europa.eu/RegData/etudes/ note/join/2013/462515/IPOL-FEMM_NT(2013)4625 15_EN.pdf.

Brito, Â. U., \& Santos, M. L. (2012). O brincar na Pedagogia em participação. Paper presented at the II Congresso Internacional de Educação Infantil (pp. 1-14),

São

Paulo. http://www3.fe.usp.br/secoes/inst/novo/agenda _eventos/inscricoes/PDF_SWF/11438.pdf.

Fernández, G. T., \& Sanchez, M. C. A. (2009). 2.Coeducación (pp. 78). Retrieved from http://www.oei.es/genero/documentos/niveles/E ducacion_Infantil/Coeducacion_en_EInfantil.pdf.

Ferreira, S. A., \& Salvaterra, F. (2004). Filho do coração...: Adopção e comportamento parental. Análise Psicológica, 22(2), $13 . \quad$ Retrieved from http://www.scielo.mec.pt/pdf/aps/v22n12/v22n1 2a08.pdf.

Figueiredo, M., Morais, S., \& Garcia, J. (2005). "Para aprender é preciso pensar": diálogos sobre a aprendizagem com crianças de cinco anos. Paper presented at the VIII Congresso Galaico-Português de Psicopedagogia (pp. 3039-3050), Braga. http://www.educacion.udc.es/grupos/gipdae/do cumentos/congreso/viiicongreso/pdfs/361.pdf.

Frade, A., Marques, A. M., Alverca, C., \& Vilar, D. (2009). Educação sexual na escola: guia para professores, formadores e educadores (pp. 160).

Hohmann, M., \& Weikart, D. P. (1997). Educar a Criança. Lisboa: Fundação Calouste Gulbenkian.

IPPF, E. N. (2006). Sexuality Education in Europe: a reference guide to policies and practices. Brussels Retrieved

from http://www.ippfen.org/Resources/Publications?p age $=1$.

Jacob, E. (1998). Clarifying Qualitative Research: a Focus on Traditions. Educational Researcher, 17(1), 12. doi:10.3102/0013189X017001016

Louro, C. F. (2012). Os maus tratos a crianças: representações das crianças sobre a família e o risco psicossocial. (Dissertação de Mestrado), Faculdade de Ciências Sociais e Humanas, Universidade Lusófona de Humanidades e Tecnologias, Lisboa, Portugal. http://recil.grupolusofona.pt/handle/10437/5 009.

Marques, A. M., Vilar, D., \& Forreta, F. (2002). Os afetos e a sexualidade na educação pré-escolar - um guia para Educadores e Formadores ( $1^{\mathrm{a}}$ ed. Vol. 23). Lisboa: Texto Editores.
Marques, R. (2001). Educar com os pais. Lisboa: Editorial Presença.

Matos, J. (2006). O sexo contado aos pequenos. Porto: Nova Variante.

ME-GTES. (2007). Relatório Final do Grupo de Trabalho de Educação Sexual. Retrieved from Lisboa: www.dge.mec.pt/sites/default/files/ficheiros/r elatorio_final_gtes.pdf

Ministério da Educação, Ministério da Saúde, APF, \& CAN. (2000). Educação sexual em meio escolar: Linhas orientadoras. Lisboa: Ministério da Educação e Ministério da Saúde.

Morales, G. H., \& Guijarro, C. J. (2003). La educación sexual de la primera infância: guia para madres, padres y profesorado de educación infantil (Vol. 155). Espanha: Ministério de Educación, Cultura y Deporte.

Oliveira-Formosinho, J. A., Sara Barros. (2004). O envolvimento da criança na aprendizagem: Construindo o direito de participação. Análise Psicológica, 22(1), 13. doi: 10.14417/ap.132

Ostermann, F., \& Cavalcanti, C. (2010). Teorias de aprendizagem (pp. 40). Retrieved from http://www.ufrgs.br/uab/informacoes/publicacoe s/materiais-de-fisica-para-educacao-basica/teorias_de _aprendizagem_fisica.pdf.

Rights, U. N. H. (2004). Human Rights Topics for Upper Primary and Lower and Senior Secondary School. In U. N. Publication (Ed.), ABC - Teaching Human Rights: Practical activities for primary and secondary schoolsHuman Rights Education Series (Vol. 4, pp. 27). New York and Geneva. Retrieved from http://www.ohchr.org/EN/PublicationsResources /Pages/TrainingEducation.aspx.

Souza, J., Kantorski, L., \& Villar Luis, M. (2011). Análise documental e observação participante na pesquisa em saúde mental. Revista Baiana de Enfermagem, 25(2), $8 . \quad$ Retrieved from http://unisc.br/portal/upload/com_arquivo/analis e_documental_e_observacao_participante_na_pesquis a_em_saude_mental.pdf.

Spodek, B. (2002). Manual de Investigação em Educação de Infância (pp. 119-166). Coimbra: Fundação Calouste Gulbenkian.

Vilar, D., \& Ferreira, P. M. (2009). A educação sexual dos jovens portugueses-conhecimentos e fontes. Revista Educação Sexual em Rede, $n^{\circ}$ 5, 51. http://www.apf.pt/?area=002\&mid=004\&sid=004.

WHO. (1999). Health 21: the health for all policy framework for the WHO European Region. Retrieved from http://www.euro.who.int/en/publications/abstract s/health21-the-health-for-all-policy-framework-for-th e-who-european-region.

Winston, R. (2004). Porque sou o que sou? Porto: Editora 